\title{
Quoting from the case file: How intertextual practices shape discourse at various stages in the legal trajectory
}

\author{
Sigurd D'hondt \\ Ghent University \\ Fleur van der Houwen \\ VU University, Amsterdam
}

\begin{abstract}
Criminal trial hearings are communicative events that are densely intertextually structured. In the course of a trial hearing, written documents such as police records of statements made by suspects, witnesses and experts are extensively referred to, quoted, paraphrased, summarized and recontextualized. In fact, such drawing upon the (written documents in) the case file is inevitable, as demonstrating (or invalidating) the defendant's criminal liability crucially depends on the transformation of discourses produced at previous stages of the trial into lawful evidence. Detailed analyses of the various discursive processes through which intertextual links with the case file are established are thus essential for understanding exactly how trial participants negotiate versions of events with specific legal implications. In this special issue we bring together a collection papers that deal with such intertextual practices in different legal settings.
\end{abstract}

\section{Intertextuality in the legal process}

The intertextual practices that connect a trial hearing to the various discourses produced in preparation for the trial are complex and multilayered. A first complicating element is the fact that the institutional aims of the various legal actors are not the same. Different participants at the trial will establish differing intertextual connections depending on their professional role. Prosecutors aim to demonstrate the defendant's liability while lawyers aim to minimize it; judges have their own specific role in establishing "the truth", depending on the legal system in question. Second, there is the fact that criminal hearings do not come out of the blue; rather, they represent one step in a bureaucratically organized chain of events. This, too, has its impact on the specific form quoting practices in the courtroom take.

This last point deserves some further clarification. Criminal adjudication can be characterized as a process of gradual discursive transformation: Throughout the successive stages of the trial (e.g. investigation by the police, the prosecutor's decision to take the case to court, the hearing), professional legal actors are working together (or, depending on the specific stage, against one another) to assign the "facts" which the defendant is tried for (situated conduct that is inextricably tied to the specifics of the setting in which the facts were committed and is thus deeply "local") to one of the abstract categories of criminal law 
(Matoesian, 2001; Dupret, 2011; see also Maynard and Wilson, 1980). The trial hearing represents a crucial stage in this gradual transformation, because the proposed legal categorization of the defendant's conduct becomes a binding legal reality only after the defendant has the opportunity to publicly defend him/herself against the accusation (and after the applicability of the relevant category of criminal law has been endorsed by the judge in the verdict).

The above already affords us a first glimpse of the complexity of the network of intertextual relationships that are played out in the courtroom by the various participants. On the one hand, demonstrating (or invalidating) criminal liability always involves a form of reconstruction of the facts of the case, including the defendant's linguistic conduct at the time of the facts. In this sense, the relationship between the hearing and the facts that are being discussed very much resembles the classic distinction between reporting and reported event: the hearing is a discursive arena where remote speech events are recounted.

On the other hand, however, deciding the applicability of the proposed legal category would be impossible without the written records that contain an officially certified version of the facts of the case. These documents consist primarily of police records of statements by suspects, witnesses and experts, and are collected in the case file. These are the discourses produced in preparation for the trial which are extensively referred to, quoted, paraphrased, summarized or otherwise recontextualized in the course of the trial (in order to be accepted by the court as lawful evidence). This obviously complicates the relationship between the reporting and reported event postulated earlier: In reporting what the defendant allegedly said or did in the course of the incident for which he or she has to stand trial, the prosecutor, defense attorneys and other trial participants are not directly quoting the reported event itself, but are instead relying on third parties' reports of that event.

Importantly, these third-party reports that are cited in the course of the hearing have a life of their own, a "natural history of discourse" (Silverstein and Urban, 1996) that accrues as they move from one context to another in the progression of the trial. In this sense, these texts indeed "travel," as the title of a recent edited volume (Heffer et al., 2013) suggests: They gradually proceed through the successive contexts (interrogation, compiling the indictment, the trial hearing, the verdict) which together make up the textual "trajectory" (Blommaert, 2005) characteristic of criminal adjudication. However, the notion of texts as entities "travelling" through the legal space ought also to be taken with a grain of salt. Earlier research extensively demonstrated the illusory character of the idea that documents moving along the legal chain are stable objects that have a fixed character. The assumption that a document quoted in court is a stable entity "hides the diachronic instability of the discourse from which text emerged" (Rock et al., 2013: 3). Throughout the various nodes of the legalbureaucratic trajectory of a text, discourses are continually appropriated by new legal actors who subject them to "de-" and "recontextualization" (Bauman and Briggs, 1991), as they insert these discourses in their new textual environment - a process that goes hand in hand with subtle transformations that may nevertheless have strong legal consequences and that are open to strategic manipulation (for some particularly vivid examples, consider Matoesian, 2001; Ehrlich, 2007; Haket, 2007).

The current special issue further elaborates this dual theme - the hearing as an intertextual event, that is in turn part of an ongoing process of textual transformation. It 
brings together a number of papers that all deal with quoting and associated intertextual practices as they come about in legal settings. Some of them were presented at the panel "Quoting from the case file" organized at the XIth IPrA conference in Manchester (3-8 July, 2011), while others originated in the context of the research project "Intertextuality in judicial settings" at the VU University in Amsterdam, the Netherlands (NWO project number 360-70240). Together, the different papers offer a broad picture of quoting practices in various legal settings, spanning different countries with diverse legal systems. They also document different key moments within the course of the criminal trial, which draws further attention to the bureaucratic requirements and contextual contingencies by which reporting practices are shaped.

\section{Different legal settings}

In this special issue we have aimed to bring together papers that analyze intertextual practices in different legal settings and different legal systems. There is one paper, by Van Charldorp, that focuses on the very beginnings of the intertextual chain. While the other contributions describe how quoting and associated intertextual practices transform written text into talk, van Charldorp's takes exactly the opposite route. Her analyses of police interrogations of petty crime suspects document how the officers in charge of the interrogation transform talk into written documents, which will later be used as evidence in court. Her paper describes the context in which the documents are produced that the quoting parties later rely on in court, and as such it forms an essential counterpart to the other papers that analyze how these documents are quoted higher up in the chain.

The other authors who contributed to this issue specifically address the discursive processes by which interactions on prior occasions are imported into the discourse of courtrooms, although in different legal settings. One contribution documents a particularly vivid instance of intertextuality in an adversarial setting. Johnson's paper draws its data from the much publicized Harold Shipman trial, which lasted 51 days and resulted in the conviction of the British general practitioner on the count of the assassination of fifteen patients. In her analysis, she documents how the judge, at the end of the trial, summarizes the evidence for the jury; in doing so, he juxtaposes oral testimony that was presented to the court in the course of the hearing with reenactments in court of transcripts of police interviews.

The papers by Van der Houwen and Sneijder, Maryns, and D'hondt document practices of quoting in a continental, mixed inquisitorial-adversarial legal system (the Netherlands and Belgium, respectively). Van der Houwen and Sneijder, and also D'hondt, present data from courts where criminal cases are adjudicated by professional judges, where there are only sporadic in person examination of witnesses in court, and the judge, prosecutor, attorney and other professional trial participants rely almost exclusively on written documents produced prior to the hearing, in the course of the criminal investigation. Maryns' paper, however, describes the intertextual construction of insanity in a murder case that appeared before a Belgian Assize Court trial. Here, the entire investigation is orally reenacted before the eyes of the jury.

Licoppe's contribution stands apart, as his paper tackles a legal setting that is strictly speaking not a trial and represents a recent innovation in the French legal system: "future 
dangerousness assessment hearings" in which a panel of experts, presided over by a judge, must determine whether an inmate who committed a violent crime poses a risk of recidivism or whether he or she should be allowed to return to society. Consequently, the documents that participants in these hearings quote from are not police reports, but expert testimony that was commissioned by the committee responsible for these assessments. The hearings are additionally complicated by the fact that inmates are usually not physically present. Instead, he or she participates in the hearing through a video link.

\section{Different methodological commitments}

Four of the six papers in this issue (Licoppe, Van der Houwen and Sneijder, Van Charldorp, and D'hondt) subscribe to the analytical concerns and methodological commitments of ethnomethodological conversation analysis (CA) — even though they occasionally also borrow concepts such as footing and narrative from authors like Goffman and Labov if these turns out useful for elucidating participants' practices. The paper by Van der Houwen and Sneijder takes a conversation analytical approach to analyze the interaction between the judge and suspect but also draws upon insights from discursive psychology (e.g. Edwards and Potter, 1992) to analyze the statements by the prosecutor and lawyer.

What these authors have in common is that they approach the textual chain as something that is formulated, at least partially, within the talk itself, much in line with the classic CA position on issues of context (see, e.g., Schegloff 1992). Thus, Licoppe, Van der Houwen and Sneijder, and D'hondt describe how participants in a hearing, in quoting from the case file, reflexively connect that hearing to a particular, pre-existent legal-bureaucratic textual trajectory. In the very act of doing so, the participants inevitably present a specific version of that trajectory, as their quoting is based on, and hence "makes public," a particular interpretation of how that case is based on a variety of written documents. A similar observation can be made regarding Van Charldorp's discussion of how talk is transformed into text in police interrogations, which focuses on the very beginning of the intertextual chain. Her paper demonstrates that assembling a written report is not something that happens post factum, but is very much a matter of relevant concern in the face-to-face organization of the interview itself. Here as well, then, the intertextual chain features as an object of attention already "within" the interaction.

The papers by Johnson and Maryns approach reporting practices from a slightly different angle. While Maryns adopts a broadly linguistic-anthropological perspective on what she calls "interdiscursivity" (which, in addition to explicit intertextual linkages, also includes more implicit correlations between discourses), Johnson's contribution is the one that stands methodologically most apart. Her paper illustrates what Partington et al. (2013) refer to as a Computer-Assisted Discourse Studies approach (CADS), which involves the back-and-forth tracking between (1) distributional observations on the lexical items selected by the judge for organizing and introducing his references to the oral testimony produced during the forty trial days that preceded and (2) in-depth analyses of selected discourse fragments.

\section{Intertextual practices: Trends and themes}

In the remainder of this introduction, we try to unravel some of the themes that are recurrent throughout the various contributions to this special issue. 


\subsection{The variety of intertextual practices (and their context-dependency)}

At one level we can distinguish three types of intertextual practices, as relevant to the legal settings analyzed in this special issue: 1) reporting practices that go from talk to text, as is exemplified in the paper by Van Charldorp, 2) reporting practices that go from text to talk, as is exemplified in various of the other papers, and 3) reporting practices that go from talk to talk, which can be found, for example, in the analyses of jury trials by Johnson and Maryns.

At another level we can distinguish, regardless of the "direction" of the reporting (talktext, text-talk, talk-talk, text-text), between direct and indirect reported speech. The main difference between these two reporting strategies lies in their deictic orientation. Direct reported speech retains the deictic center of the original utterance: The latter preserves its original deictics and the quoted discourse thus firmly anchors itself in the reported event (e.g. the police station, or the event for which a suspect has been arrested). For indirect reported speech, however, it is the reporting event (for instance, the courtroom) that becomes the deictic center of the quoted utterance (and deictic forms of that utterance shift accordingly, such that $1^{\text {st }}$ sing. $I$ becomes $3^{\text {rd }}$ sing. she or he, etc). The contrast between the two, then, lies in the fact that for direct reported speech, the reported event is "drawn into" the reporting event. In legal contexts, direct reported speech has been found to foreground the information it reports (Philips, 1986; Van der Houwen, in press; see also Johnson, this issue).

There are good reasons to assume, however, that the choices language users face in choosing a particular strategy are more complex than this binary distinction suggests. Thus, in the literature there is a longstanding discussion over a "third option", variously referred to as "free indirect" or "represented speech" (see, e.g., the discussion in Coulmas, 1986, p.6ff). It might be more fruitful, therefore, to think of reporting strategies as comprising a scale, ranging from more indirect ones such as summarizing, paraphrasing, and indirect reporting, to more direct ones such as direct reported speech with verbum dicendum and without, resulting in reenacted direct reported speech. Many of the papers in this issue also point in this direction, as they strongly emphasize the local specificity and local variety of reporting practices. They show how the intertextual connections that are forged with prior discourses are sensitive to the specific institutional character of the legal setting, and document in detail how these connections exploit the interactional opportunities which the specific "node" of the legal chain that is being investigated offers to the quoting agents. For obvious reasons, the resulting picture of reporting practices resists reduction to simple binary schemata. Thus, Johnson, in a discussion of how the judge makes use of the contrastive use of different forms of reported speech for organizing his summary of the evidence for the jury, throws in an until now undocumented third option which she characterizes as the "re-enactment" of entire question-answer sequences. In an entirely different setting (French "dangerousness assessment hearings"), Licoppe distinguishes two different strategies that judges routinely choose between for referring to written expert testimony collected in the file before them: "indirect reported text" (in which "written claims about the defendant are conveyed through the voice of other parties", p. TO BE SUPPLIED LATER) and "text as addressed speech" (in which written claims are re-enacted as explicit assessments of the inmate appearing in front of them). D'hondt's analyses of footing shifts in the closing statement by a defense attorney in a Belgian first-instance court also presents a more subtle and more context-sensitive ways 
of embedding courtroom discourse in the chain of discourses that preceded it. A similar observation can be made for Maryns account of interdiscursivity in Belgian jury trials.

\subsection{The presumed invisibility of reporting agents}

It has repeatedly been observed that the subsequent de- and recontextualizations to which texts are subjected as they travel up and down along the textual chain, and the mediating agents that are responsible for these successive interpretative operations, remain largely unnoticed. Other research has shown, both in adversarial (e.g., Matoesian, 2001; Ehrlich 2007) and inquisitorial legal systems (e.g., Sneijder 2011, Van der Houwen 2013), that the prevailing "referentialist" linguistic ideology (which holds that the meaning of quoted discourse exclusively resides "inside the words" of the quoted text) entirely draws out of sight the strategic recontextualizations which this text is subject to as it is incorporated in the speaker's new discourse. Direct reported speech, in which the speaker at first sight merely "animates" (Goffman 1981) what another speaker presumably said, thus allows legal actors to subtly fuse the quoted discourse with their own voice - which is why it constitutes such a powerful rhetorical device. According to Matoesian (2001), reported speech "shapes testimony" as it transforms prior utterances into evidence and imbues them with affective meaning, in this process naturalizing discursive authority and attributing social identities to the trial participants. Reported speech and related intertextual practices therefore constitute "the evidential infrastructure of the adversarial system of justice" (2001: 105).

The contributions to this issue demonstrate that cross-examination and the presentation of the evidence in court (described, for example, in Matoesian's work) are not the sole stages in the chain where the agency of the reporting agents (and the mediating role other agencies that transmitted the discourse at earlier stages in the textual chain) is downplayed and rendered invisible. In those legal systems that do not allow for the tape recording of interrogations, for example, reporting officers routinely produce monologized version of dialogical interaction that nevertheless present themselves as if they are a faithful rendition of what the defendant said (Komter, 2013), which are subsequently treated as such by actors higher up in the legal chain (Komter, 2013; Maryns, 2013).

The papers by van Charldorp (on police interrogations), and by Van der Houwen and Sneijder, Maryns, and Johnson (on courtroom talk) further elaborate this theme. Whereas previous research focused on the invisible agency of the textual mediator in adversarial legal systems, the papers by Van der Houwen and Sneijder, Maryns, and Johnson demonstrate such agency to be also at work in inquisitorial legal systems (Van der Houwen en Sneijder, Maryns) and in those stages of the adversarial trial where textual mediation is supposed to be neutral (Johnson).

Thus, Johnson's paper on the Shipman trial presents a vivid picture of the way in which the judge, in "summarizing" the evidence for the jury, constructs a powerful "polyphonic monologue" that leaves jury members no other option than to find the defendant guilty. The contribution by Van der Houwen and Sneijder highlights the selectivity of the reporting agents, as each party quotes those voices that support their own version of what happened. Maryns describes how interdiscursivity allows a defense attorney to renegotiate the meaning of a category of criminal law, in this case insanity, which is undefined from a legal perspective. Van Charldorp, finally, approaches the issue from a slightly different angle. Her 
paper documents the various formats which a police interrogation of the suspect of a minor offense may take, the bottom line being that the written records of these interrogations fail to do justice to the interactive, highly dialogical contexts in which they came about. Here, the mediating agency that is rendered invisible is not the courtroom participant who quotes the written report, but the police officer who put the report together.

\subsection{The intertextual trajectory as interactional resource}

Quoting thus generally proceeds under the assumption of textual stability across contexts, yet some contributors proceed in a direction that suggests precisely the opposite. Their work raises the possibility that the invisibility of mediating agencies in compiling records of what happened might somehow be less absolute than the above suggests. It proposes that this invisibility is a matter of degree that is contextually variable, and that it is very much a matter of strategic choice whether or not to act upon a piece of text as if it were a literal rendition of what someone else said. Participants to a hearing may, to the contrary, also draw attention to the particular circumstances under which the text was produced and to the subsequent recontextualizations to which it was subjected (for example, by "animating" it in a way that suggests insincerity on the part of the party who drafted the record). They hence exhibit, in the very details of their intertextual practices and in the way they quote other parties' talk, an acute reflexive awareness of the textual trajectory the quoted materials go through and of the fact that they "passed through many hands", each of which entails an opportunity for strategic manipulation. In this sense, the intertextual trajectory of the quoted text becomes an interactional resource.

Licoppe, for example, in his discussion of the way judges use "indirect-reported-text" in the initial summaries of expert testimony they produce at the start of dangerousness assessment hearings, demonstrates how "differences in the choice of reporting agency [...] reflects the length of the chain of mediations involved in the production and the spoken reenactment of the file" (p. TO BE SUPPLIED LATER). Through the choice of the specific formulation by which the reported text is introduced, judges may either draw attention to the expert who authored the report of the inmate's examination, or to their own reading of the report. Alternatively, he or she may also decide to treat the examination of the defendant as just another speech event (e.g., in which he or she voiced a particular opinion), thus leaving the chain of mediations out of the picture altogether. Thus, "within the frame of indirect reported text, the variety of ways in which the president refers to the file during his initial summary makes relevant in different ways the network of mediations, agencies and language activities that link the initial interviews with various professionals and the current context of his spoken reference, and which the file documents" (ibid.).

D'hondt's analysis of footing patterns in a not-guilty plea further elaborates this theme. Different segments of the plea project different phenomenal fields. They can be distinguished, for example, on the basis of whether the defense attorney emerges as an independent character in the discourse (who produces an "impartial" assessment of the accusation) or whether he or she presents him/herself as merely "animating" the client's voice. Furthermore, the way the client-attorney relationship is enacted through footing cannot be separated from the wider participation frameworks which the plea projects (the role it attributes to the judge, the prosecutor, the audience, etc.) and from the particular perspective 
on the legal-bureaucratic textual trajectory that it puts forward. Footing patterns can thus additionally be distinguished on the basis of whether they background the case file (e.g., when the attorney merely "relays" the client's position) or whether the case file emerges as an explicit object of attention (e.g., when he or she "enters into a dialogue" with a police statement). In those segments where the attorney enters into a dialogue with the case file, direct quotes from the police record often serve the function of drawing attention to the particular circumstances under which the case against the client was put together. They maximize the distance between reported and reporting event, suggesting that the written record (the "mediating step" between reporting and reported event) was manipulated by the arresting officers with an eye on its later use in court.

Like in the papers that we discussed in 4.2 , however, this use of direct reported speech to underscore the insincerity of the quoted discourse is still based on the ideology that the attorney's quote constitutes a faithful rendition of the written record that is being referred to. It may thus well be possible to highlight the mediating agency of other actors in the legal chain (in the case of instances of direct-reported-text discussed by Licoppe) or to openly challenge the validity of the mediating textual link (in D'hondt's case), but such explicit orientations to the textual trajectory of the quoted materials do itself not invalidate the "intertextual authority of reported speech" (Matoesian 2000: 879).

Put next to one another, these papers draw attention to yet another manner in which the legal-bureaucratic character of legal settings affects the shape quoting in the courtroom may take. They highlight the possibility that intertextual practices may creatively exploit the intertextual distance between reporting and reporting event, and this constitutes an additional parameter on which various practices of quoting can be differentiated.

\subsection{The multiple involvements of the reporting agent}

Another element that further complicates quoting practices in courtrooms, partially related to the previous point, is the fact that the setting in which such quoting takes place is usually a lot more complex than the protocols for courtroom hearings suggests. It is by now commonplace that quoting must be analyzed in terms of the pragmatics of the local speech situation and the way it contributes to the interactional unfolding of the reporting event (for a specifically conversation-analytic version of this claim, see the various contributions in Holt and Clift, 2007). In the various legal settings documented in this issue, this argument assumes a particular twist precisely because of the fact that quoting and related intertextual practices are specifically attuned to the equivocality of the participation frameworks courtroom participants operate and the fact that they are somehow less stable than the bureaucratic character of the setting suggests. That is, legal actors, and also the lay participants with whom they interact, often find themselves aligned towards one another on the basis of participation frameworks that are highly equivocal, as these frameworks position the participants vis-à-vis one another on the basis of multiple involvements.

Licoppe's distinction between indirect-reported-text and text-as-addressed-speech, for example, must be seen in the light of the highly "reflexive" character of the case summaries that judges produce at the start of dangerousness assessment hearings. Reflexivity here refers to the dual status of the inmate appearing before the commission, i.e., the fact that he or she is at once the object of the written expert assessments re-enacted by the judge and the recipient 
of these reenactments. Indirect-reported-text and text-as-addressed-speech, then, represent different ways of attending to this tension. From a slightly different angle, D'hondt's analysis of footing shifts in a not guilty plea demonstrates that attorneys creatively exploit the mixed inquisitorial-accusatorial nature of Belgian criminal hearings as maneuvering space for continually readjusting their relationship to the client and the other courtroom participants. The paper by Van Charldorp teaches us that this multiplicity of involvements in which the reporting agent is entangled is not restricted to courtroom hearings hearing, but is also characteristic of other stages in the textual chain. Police officers who interrogate a suspect, for example, must continually juggle between keeping the interaction going with a coparticipant whose prime concern is to demonstrate the ordinariness of his or her conduct and writing a document (the suspect's statement) that meets the procedural requirements of lawful evidence.

Maryns' paper, finally, addresses a topic that since Conley and O'Barr's (1990) seminal work has become a recurrent theme in studies of language and the law: the lingering conflict between professional and lay perspectives on what is going on inside the courtroom. Her analysis of a defense lawyer's intertextual strategies for negotiating the meaning of a legal concept (and imbuing it with a set of commonsense understandings) brings to light the intermediary role of legal actors in a jury trial, in particular the fact that they must continually navigates the tension between professional and everyday understandings of the legal process.

\section{Conclusion}

With this special issue we hope to have contributed to the further understanding of how texts in the legal process come about, how they are drawn upon by different legal professionals further along in the legal trajectory, so as to highlight the role they play in legal decision making. It is obviously a tricky exercise trying to summarize six different papers on the basis of four different themes that we believe to be recurrent. Therefore, we would like to invite the reader to explore for him- or herself how the various authors have attended to the issue of intertextuality in legal contexts. Together, the papers collected in this issue, in spite of the limitations that are inherent in having to make a selection between different settings and various legal systems, offer us at least a glimpse of the way intertextual practices shape legal discourse, each at the specific point in the textual chain that it addresses.

To round of, we would like to point out that the intertextual practices documented here are not only interesting from a fundamental scientific perspective, but that they also have real world implications for those who are part of the justice process as either suspect or witness; implications that may not always be stated explicitly in the different papers, but which we would do well to share with those in the professional field that we study.

\section{References}

Bauman, R., Briggs, C., 1990. Poetics and performance as critical perspectives on language and social life. Annual Review of Anthropology 19, 59-88.

Blommaert, J., 2005. Discourse: A Critical Introduction. Cambridge: Cambridge University Press. 
Conley, J. C., O’Barr, W., 1990. Rules vs. Relationships: The Ethnography of Legal

Discourse. University of Chicago Press, Chicago

Coulmas, F., 1986. Reported speech: Some general issues. In: Coulmas, F. (Ed.), Direct and Indirect Speech. Berlin, New York, Amsterdam: Mouton de Gruyter, pp. 1-28.

Dupret, B., 2011. Adjudication in Action: An Ethnomethodology of Law, Morality, and Justice. Farnham: Ashgate.

Edwards, D., and Potter, J., 1992. Discursive Psychology. Sage, London.

Ehrlich, S., 2007. Legal discourse and the cultural intelligibility of gendered meaning. Journal of Sociolinguistics 11(4), 452-477.

Goffman, E., 1981. Footing. In: Forms of Talk. Oxford: Blackwell, pp. 124-159.

Haket, V. T., 2007. Veranderende verhalen in het strafrecht: De ontwikkeling van verhalen over verkrachting in het strafproces. Netherlands Institute for the Study of Crime and Law Enforcement (NSCR), Faculty of Law, Leiden University.

Heffer, C., Rock, F., Conley, J. (Eds.), Legal-Lay Communication: Textual Travels in the Law. Oxford: Oxford University Press.

Holt, E., Clift, R. (Eds.), Reporting Talk: Reported Speech in Interaction. Cambridge:

Cambridge University Press

Komter, M. L., 2013. Travels of a Suspect's Statement. In: Heffer, C., Rock, F., Conley, J. (Eds.), Legal-Lay Communication: Textual Travels in the Law. Oxford: Oxford University Press, pp. 126-146.

Maryns, K., 2013. 'Theattricks' in the courtroom: The intertextual construction of legal cases. In: Heffer, C., Rock, F., Conley, J. (Eds.), Legal-Lay Communication: Textual Travels in the Law. Oxford: Oxford University Press, pp. 107-125.

Matoesian, G., 2000. Intertextual authority in reported speech: Production media in the Kennedy Smith rape trial. Journal of Pragmatics 32 (7), 879-914.

Matoesian, G., 2001. Law and the Language of Identity: Discourse in the William Kennedy Smith Rape Trial. Oxford: Oxford University Press.

Maynard, D. W., Wilson, T. P., 1980. On the reification of social structure. Current Perspectives in Social Theory 1, 287-322.

Partington, A., Duguid, A., Taylor, C. 2013. Patterns and Meanings in Discourse: Theory and Practice in Corpus-assisted Discourse Studies (CADS). Amsterdam: John Benjamins.

Philips, S. U., 1986. Reported speech as evidence in an American trial. In: Alatis, D. (Ed.), Languages and Linguistics: The Interdependence of Theory, Data and Application.

Georgetown University Press, Washington DC, pp. 154-170.

Rock, F., Heffer, C., Conley, J., 2013. Textual travel in legal-lay communication. In: Heffer, C., Rock, F., Conley, J. (Eds.), Legal-Lay Communication: Textual Travels in the Law. Oxford: Oxford University Press, pp. 3-32. 
Schegloff, E. A., 1992. In Another Context. In: Duranti, A., Goodwin, C. (Eds.), Rethinking Context: Language as an Interactive Phenomenon. Cambridge: Cambridge University Press, pp. 193-227.

Silverstein, M. Urban, G. 1996. The natural history of discourse. In: Silverstein, M. Urban, G. (Eds.), Natural Histories of Discourse. Chicago: University of Chicago Press, pp. 1-17.

Sneijder, P., 2011. Citaten in requisitoir en pleidooi: een retorische structuur. Tijdschrift voor Taalbeheersing 33 (1), 55-68.

Van der Houwen, F., 2013. Reported writing in court: putting evidence 'on record'. Text \& Talk 33(6), 747-769.

Van der Houwen, F., in press. The fore- and backgrounding of information: reporting practices by judges in criminal court. In: Sousa-Silva, R; Faria, R; Gavaldà, N; Maia, B. (Ed.). Proceedings of the 3rd European Conference of The International Association of Forensic Linguistics. Bridging the Gap(s) between Language and the Law. Universidade do Porto, Porto. 